Military Technical College

Kobry Elkobbah,

Cairo, Egypt

May 27-29,2008

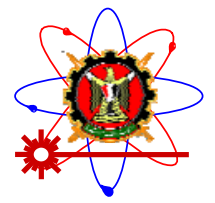

$4^{\text {th }}$ International Conference on

Mathematics and Engineering

Physics (ICMEP-4)

\title{
WP1
}

\section{Light Sources and its Medical Applications}

Farouk Hamouda, and Sayed Sief

\begin{abstract}
Nowadays, Light Emitting Diodes (LEDs) are fast becoming the light source of choice for medical application. LED therapy has been performed to investigate the influence of LEDT on the healing process of wounds or lesions. The researchers reported that light therapy as LEDT has a biostimulative effect and greatly enhance the natural wound healing process.

This will save valuable time and resources for both patients and health care facilities. Furthermore, improved wound healing will reduce the risk of infection for the patient, decrease the amount of costly dressings required, and more quickly return the patient to a preinjury/ illness level of activity; also laser light has been widely acclaimed to speed wound healing of ischemic, hypoxic, and infected wounds. LEDs provide low energy stimulation of tissues that result in increased cellular activity during wound healing; these activities include collagen production and angiogenesis.
\end{abstract}

